\title{
Reasons for (not) discontinuing antipsychotics in dementia
}

Sarah I.M. Janus, MSc, Jeannette G. van Manen, PhD, Sytse U. Zuidema, Prof, Carina Snijder, MSc, Constance H.C. Drossaert, PhD \& Maarten J. IJzerman. Prof

${ }^{1}$ Department Health Technology and Services Research, University of Twente, P.O. Box 217, 7500 AE Enschede, The Netherlands

${ }^{2}$ Department of Psychology, Health and Technology, University of Twente, P.O. Box 217, 7500 AE Enschede, The Netherlands

${ }^{3}$ Department of General Practice, University of Groningen, University Medical Center Groningen, Groningen, the Netherlands

Corresponding author: Sarah Janus, University of Twente, Health Technology and Services Research, PO Box 217, 7500 AE Enschede, the Netherlands. Email: s.i.m.janus@utwente.nl, phone number +31534893915

Running head: Overview of determinants

The manuscript is submitted to the field 'BPSD and Non-pharmacological Therapy' of the journal.

This is the author manuscript accepted for publication and has undergone full peer review but has not been through the copyediting, typesetting, pagination and proofreading process, which may lead to differences between this version and the Version of Record. Please cite this article as doi: $10.1111 /$ psyg.12280

This article is protected by copyright. All rights reserved. 


\section{Abstract}

Background: The gap between high antipsychotic prescription rates for patients with dementia and the guidelines' advice to prescribe cautiously indicates that barriers exist that hampers discontinuation. This exploratory study gives a first overview of influencing factors for physicians for discontinuing antipsychotics in nursing home patients with dementia using the Theory of planned behaviour.

Methods: 41 physicians in The Netherlands completed an online survey which was based on the Theory of Planned Behavior.

Results: Half of the respondents agreed that antipsychotics have positive consequences for the patient, such as calming effects. Physicians who indicated that they discontinue antipsychotics less frequently believed more often that antipsychotics are associated with positive consequences for the staff. Physicians who tend to discontinue antipsychotics had a higher perceived behavioural control than the group who indicated having a low intention.

Conclusion: To enhance discontinuation of antipsychotics, interventions should not only focus on patient-related factors. Prescribing decisions are influenced by staff-related factors and need to be addressed as well.

Key-words: dementia, psychopharmacology, nursing homes

This article is protected by copyright. All rights reserved. 


\section{Introduction}

Elderly people receiving long-term care in an institution frequently suffer from some type of neuropsychiatric symptoms over the course of the disease encompassing aggression, shouting, agitation and wandering (1). These challenging behaviours can not only lead to harm to the resident self but also to other residents and staff members (2).

Current guidelines call for psychological and social approaches as first-line treatment option for neuropsychiatric symptoms, followed by pharmacological recommendations as second-line treatment including cautious use of antipsychotics (3). In contrast to this advice the use of antipsychotics are used too often, which is an increasing concern (4-6). There is only a modest efficacy associated with antipsychotic treatment in residents with agitation or aggression $(7,8)$. Furthermore, evidence exists that antipsychotics are associated with severe adverse events $(9,10)$. However, it is estimated that more than half of the residents on antipsychotics did not receive those according to guidelines, with one in four patients having no appropriate indication (11). Furthermore, these drug consumptions are often poorly monitored $(12,13)$, which results in a usage that is high and chronic (14).

The prescription rates range between 11 and $38 \%(15,16)$, even though studies have shown that antipsychotic use can be stopped safely without a rise in challenging behaviour (17, 18). Clearly, barriers exist to put this knowledge into practice. In order to facilitate

This article is protected by copyright. All rights reserved. 
antipsychotic discontinuation/optimization, it is necessary to understand factors that influencing clinical decision making (behaviour).

A first study by (14) into potential barriers for discontinuing antipsychotic prescription for dementia patients identified several aspects encountered by general practitioners (GPS) and nurses. GPs and nurses agreed on the majority of barriers, with the most important barriers encountered by both being "Reoccurrence of behavioural problems if antipsychotics are discontinued" and "Negatively affecting the quality of life if antipsychotics are discontinued' (14).

In Azermai's study, no behavioural theory was used. Using theoretical models to study theory-based cognitions, offers the potential of a generalizable framework within which to consider factors influencing behaviour and the development of interventions to modify them. One such theoretical model - the "Theory of planned behaviour" (TPB) - (19) is validated to predict human behaviour and has been used in the literature to investigate factors associated with prescribing medications before (20).

The TPB consists of three main variables that all influence the intention, which in turn influences ones behaviour (19). These aspects are 'Attitude towards the behaviour', 'Subjective norm' and 'Perceived behavioural control' (19), The more favourable the three key variables are, the stronger the intention of performing the behaviour should be (21). Intention is assumed to be immediately preceding of behaviour (21). Attitude arises from a set of beliefs about the behavioural consequences and evaluations of the consequences. Thus, an example of such an attitude regarding this subject can be found in the belief that discontinuing will result in disease relapse or reoccurrence of behaviour $(14,22)$. Subjective norm is based on 
individual's perception of social pressures regarding the behaviour (23). Examples of such elements is the belief that family is opposed to antipsychotics (14) or the belief that one is pressured by other staff to discontinue antipsychotics $(24,25)$. Perceived behavioural control is determined by the individual's perceived ease of performing the behaviour (23). For example, this constitutes the belief of the elderly care physician, if they are able to discontinue the prescription, if they feel confident enough and if they are in control.

Therefore, in the present study, we aimed to explore influencing factors perceived by elderly care physician in discontinuing antipsychotic treatment in Dutch nursing home residents living with dementia using the TPB as a framework.

\section{Methods}

\section{Setting \& Participants}

We conducted an online survey among elderly care physicians working in nursing homes. The questionnaire was published on the website and distributed via the newsletter of the association of elderly care physicians in the Netherlands "VERENSO" (26) in May 2015. Of the approximately 1500 elderly care physicians in the Netherlands, a vast majority is a member of this association and thus had access to the questionnaire.

Instrument

Demographics and job characteristics

The socio-demographic variables in the study included: the physicians' gender, age, working experience (number of years working with dementia patients), type of nursing home (small scale, traditional or combination of both), antipsychotic use (reported percentage of

This article is protected by copyright. All rights reserved. 
patients taking antipsychotics by physicians), availability and use of alternatives to antipsychotics (see table 1).

Theory of Planned Behaviour Variables

For each construct of the TPB, items were formulated based upon literature and two interviews. The interviews were undertaken with two physicians to identify the salient beliefs (27). Before the questionnaire was distributed, the researchers and one physician determined the time to complete the questionnaire and tried to resolve any ambiguities, which eventually led to a few final amendments.

The TPB variables were all formulated as statements that could be answered on 5point Likert-type scales. Attitude was measured directly using two statements related to the desirability of prescription of antipsychotics in dementia patients, or in dementia patients with behavioural problems. Responses varied from 'highly undesirable (1)' to 'highly desirable (5)'. The two statements of the Attitude showed a moderate internal consistency $(\alpha=.65)$. Attitude was also measured indirectly, by assessing beliefs about treatment effects and beliefs about effects on staff. Beliefs about treatment effects was measured by 16 statements related to the benefits and side effects of antipsychotics (for more details see table 2). Beliefs about effects on staff was measured by 6 statements related to the possible effects of antipsychotics for the staff (see table 3). All statements had response options between 'totally disagree (1)' and 'totally agree (5)'. Both indirect attitude scales showed a good internal consistency with a Cronbach's alpha ( $\alpha$ ) of .86 and .73 respectively. Items were averaged into a scale score after revising the negative items.

This article is protected by copyright. All rights reserved. 
To assess the normative beliefs physicians were asked about their perceptions of the opinions of 6 important reference persons (see table 2) regarding the discontinuation of antipsychotics $(\alpha=.80)$. In addition, physicians were also asked to indicate the extent to which these 6 reference persons were (a) explicitly asking for, or even (b) demanding discontinuation of antipsychotics. The answers on these 12 questions were averaged into a social pressure score $(\alpha=.82)$.

Perceived behavioural control was assessed using four statements. The statements assessed the perceived difficulty, perceived capability, and self-efficacy and control ('In cases where I consider it desirable, it is easy for me/ I am capable/ I am confident/ I have got the control to discontinue with antipsychotics.'). These statements were scored between 'totally disagree' (1) to 'totally agree' (5). The Cronbach's alpha's $(\alpha)$ of Perceived behavioural control is .84 , showing a high internal consistency.

Intention was measured with two items. These statements assessed if the physicians wanted or intended to reconsider the prescribed antipsychotics and stop if possible (see table 3). They could be answered on a five-point scale ranging from 'totally disagree (1)' to 'totally agree (5)'. A mean score of the two questions was calculated. Due to the skewness, the answers to this question were divided into two groups: physicians who indicated having a low intention $(<5)$ and physicians who indicated having a high intention to discontinue prescribing antipsychotics $(>5)$. The average of the two items generated the total intention score with a Cronbach's alpha of .91.

Statistical analysis

This article is protected by copyright. All rights reserved. 
Data was analysed with SPSS 22 (Statistical Package for the Social Sciences). The mean scores were calculated for each construct. Group comparisons were performed with a t-test for independent groups. Levels of significance were set at $p<0.05$.

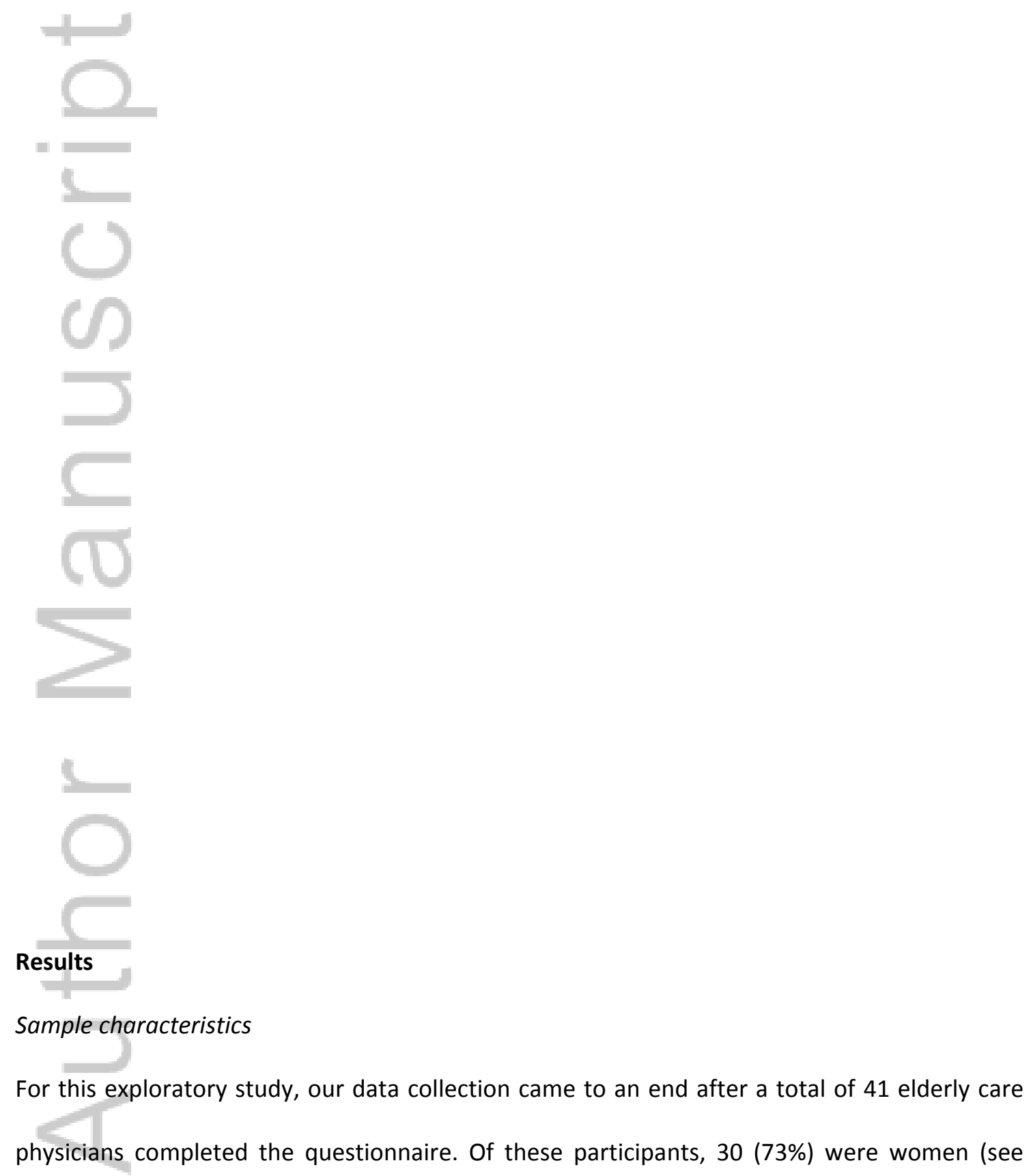

This article is protected by copyright. All rights reserved. 
table 1 ). They were on average 47 years old $(S D=10)$ and had on average 16 years $(S D=9)$ of experience in the elderly care. Almost half of the physicians were working in a combination of both small-scale and traditional nursing homes.

The participants indicated that (on average) $22 \%$ of the patients are prescribed antipsychotics and in none of the cases more than $60 \%$. Almost $85 \%$ of the elderly care physicians indicated that antipsychotics are prescribed to $30 \%$ of their patients at most. The availability and use of alternatives to antipsychotics are shown in Table 1. All therapies are available and used as indicated by more than $70 \%$ of the respondents. The therapy that is highly available is 'Medication' (95\%). The alternatives that are most used, are; 'Occupational therapy' (93\%) and 'Medication' (93\%).

Intention to discontinue antipsychotics

The scores on intention are shown in Table 3. A vast majority of the respondents reported that they want and are inclined to reconsider the antipsychotics prescribed (65\%).

Beliefs about discontinuation: descriptive scores on TPB-variables

First, the answers on the single items underlying these determinants were more closely investigated to get a deeper understanding of the determinants for intention and behaviour (see table 2).

The measures of the direct attitude indicate that the use of antipsychotics in dementia patients was mostly regarded as undesirable (66\%). On the scale beliefs about treatment effects, the physician agreed most frequently on items related to the calming effects of

This article is protected by copyright. All rights reserved. 
antipsychotics on the patients $(49 \%)$ and lowering the risk of harm to the patient's environment (46\%). For the scale beliefs about effects on staff, the majority of physicians agreed with the items less staff distress (66\%), lower workload for staff $(51 \%)$ and less psychological burden for staff (51\%).

The underlying items of the normative belief indicate that especially most physicians (66\%) felt that nursing assistants experienced antipsychotics as positive. Almost half of the participants agreed that antipsychotics are also experienced by nurses and family members as positive (44 and $49 \%$ ). The measures of the social pressures scale indicated that according to the participants, the vast majority of reference persons disagreed with discontinuation of antipsychotics.

The most important underlying items of the perceived behavioural control were confidence, control and capability. The majority of physicians felt confident (96\%), in control $(18 \%)$ and capable $(71 \%)$ to discontinue antipsychotics. However, less than half of the participants (44\%) agreed that discontinuation was easy to execute.

Association of the TPB variables with intention and behaviour to discontinue antipsychotics

Of the TPB variables only, behavioural control was significantly associated with the intention to discontinue antipsychotics (see table 4). Physicians who indicated having a higher intention to discontinue antipsychotics had a higher mean score on perceived behavioural control (4.1 (SD 0.69)) than the group who indicated having a low intention (3.4 (SD 0.67)).

This article is protected by copyright. All rights reserved. 


\section{Discussion}

This exploratory study aimed to give an overview of the different factors perceived by elderly care physicians in discontinuing antipsychotic treatment based on the TPB. The majority of elderly care physicians in our study did not agree with several negative consequences for the patient. For instance, they did not agree that antipsychotics have negative consequences on (motor) functioning, has more suppressed emotions and becomes more sedated even though these consequences are often described in the literature $(28,29)$. In our study, the physicians are aware of some potential side effects, but did not agree on all of them. A possible explanation for this lack of awareness is that the patients in this frail population are all in a severe state of dementia and already have a high risk of falling, sit in a wheelchair or immobile, therefore these events are not necessarily attributed to the use of antipsychotics. Cornege-Blokland (30) also suggests that another explanation for this is that physicians tend to value their own subjective experience more than evidence coming from literature. Additionally, the majority of the physicians believed that antipsychotics are associated with positive consequences for the staff, such as less staff distress, lower workload and less psychological stress. It is known that staff distress is correlated with psychotropic drug use (16), which might be mirrored in the view of the respondents.

This study showed that physicians who indicated having a higher intention to discontinue antipsychotics had a higher perceived behavioural control than the group who indicated having a low intention. This might be an important starting point for the development of interventions concerning the discontinuation of antipsychotics. These 
interventions could focus on enhancing the physicians' belief that they are able to discontinue these drugs. Particularly the (un)ease of discontinuing could be addressed, since on the other hand physicians mention that they feel confident and capable of discontinuing antipsychotics. More research should be performed on how to facilitate discontinuation of antipsychotics.

The elderly care physicians in our study felt little pressure from the patients, their family or the staff to discontinue antipsychotics, while earlier studies found opposing results $(24,31)$. Feeling pressured to continue an antipsychotic drug prescription might lead to a low intention for discontinuing antipsychotics, since discontinuation could lead to problems within the health care team. This would mean, however, that physicians value others surrounding the patient (such as care staff/other patients) rather than the individual patient. Additionally, the lack of pressure felt by elderly care physicians may be due to the available alternatives, as a lack of alternatives was mentioned as a reason for feeling pressure (32). In this study, all the elderly care physicians have indicated that several alternatives are available and are also in use. Whether these alternatives are used before the use of antipsychotics is, however, unclear. These alternatives could also be used simultaneously to antipsychotics, because of the severity of the challenging behaviour, as more complex cases need a multi-level strategy (33).

Although we did not detect correlation between all variables of the theoretical framework, we believe that the framework was of additional value since it has been validated in numerous studies (34). For this study it offered a good structure and assessed the influence of new determinants such as beliefs about capabilities and social influences. These determinants were not previously investigated by Azermai (14). Additionally, the framework helped to order relevant factors for discontinuation. In hindsight, our measures of intention as 
absolute values might not measure these variables well. Social desirability and the controversy of this topic might have influenced the results.

The results of this study have some limitations. We conducted the research in a limited selection of elderly care physicians. The final sample size is not fully representative for the population of elderly care physicians in the Netherlands. However, staff characteristics such as gender, age and work experiences are comparable to previous research in Dutch nursing homes (35). Yet, we cannot rule out any selection bias. Previous research, conducted in Australia and New Zealand, indicated that female geriatricians rank more often adherence to evidence-based guidelines as important for deprescribing medications (36). Indeed in this study, the majority of the elderly care physicians stated that on average they discontinue antipsychotics within 14 weeks (12 weeks is recommended in the guidelines). The large range of answers (between 2 to 30 weeks), however, indicate a chronic use of antipsychotics, which has also been shown by Azermai (14) with an average of 27 weeks. Therefore, one should acknowledge barriers of antipsychotic discontinuation (mentioned in this study) and start discontinuation of antipsychotics in practice. Therefore, one should acknowledge barriers of antipsychotic discontinuation (mentioned in this study) and start discontinuation of antipsychotics in practice. Additional physicians characteristics might influence their decision making, such as experience. We therefore divided the sample in young $(\leq 45)$ and old physicians (>45) and looked for group differences using a t-test for independent groups $(p<0.05)$. However, we did not find any differences between the two groups regarding their scores on the TPB variables as well as intention. 
The current study only looked at the physicians' intention, which is the most important variable to predict behaviour. We did not look at behaviour, since we were only able to take reported behaviour into account. Future research should also look at behaviour, preferably the actual behaviour by checking prescription rates instead of stated past behaviour. Finally, we did not take different types of dementia into account. Physicians might prescribe differently and use different psychotropic drugs for different types of dementias. However, prescribing and discontinuing of psychotropic drugs might be mainly based on the neuropsychiatric symptoms of the patient.

Despite the limitations of this exploratory study, this study provides a complete overview of possible factors that might influence prescription behaviour according to the TPB. As such, this study may provide concrete suggestions for further research. Most importantly, the relative positive attitude of physicians regarding the expected effects of antipsychotic treatment for the persons caring for the patient and the expectation that known side effects will not occur, require confirmation and deeper insight.

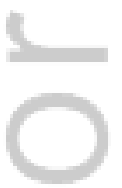

Disclosure statement: The authors have no potential conflicts of interest to disclose.

This article is protected by copyright. All rights reserved. 


\section{References}

1. Brodaty H, Draper B, Saab D, et al. Psychosis, depression and behavioural disturbances in Sydney nursing home residents: prevalence and predictors. Int J Geriatr Psychiatry. 2001;16(5):504-12.

2. Ruths S, Straand J, Nygaard HA. Psychotropic drug use in nursing homes--diagnostic indications and variations between institutions. Eur J Clin Pharmacol. 2001;57(67):523-8.

3. Azermai M, Petrovic M, Elseviers MM, Bourgeois J, Van Bortel LM, Van der Stichele RH. Systematic appraisal of dementia guidelines for the management of behavioural and psychological symptoms. Ageing Res Rev. 2012;11(1):78-86.

4. Hosia-Randell HM, Muurinen SM, Pitkala KH. Exposure to potentially inappropriate drugs and drug-drug interactions in elderly nursing home residents in Helsinki, Finland: a cross-sectional study. Drugs Aging. 2008;25(8):683-92.

This article is protected by copyright. All rights reserved. 
5. Kamble P, Chen $\mathrm{H}$, Sherer J, Aparasu RR. Antipsychotic drug use among elderly nursing home residents in the United States. Am J Geriatr Pharmacother. 2008;6(4):187-97.

6. Mann E, Köpke S, Haastert B, Pitkälä K, Meyer G. Psychotropic medication use among nursing home residents in Austria: a cross-sectional study. BMC geriatrics. 2009;9(1):1.

7. Ballard C, Corbett A, Chitramohan R, Aarsland D. Management of agitation and aggression associated with Alzheimer's disease: controversies and possible solutions. Curr Opin Psychiatr. 2009;22(6):532-40.

8. Ballard CG, Waite J, Birks J. Atypical antipsychotics for aggression and psychosis in Alzheimer's disease. Cochrane Library. 2006.

9.= Ray WA, Chung CP, Murray KT, Hall K, Stein CM. Atypical Antipsychotic Drugs and the Risk of Sudden Cardiac Death. N Engl J Med. 2009;360(3):225-35.

10. Shin J-Y, Choi N-K, Jung S-Y, Lee J, Kwon JS, Park B-J. Risk of ischemic stroke with the use of risperidone, quetiapine and olanzapine in elderly patients: a population-based, case-crossover study. J Psychopharmacol. 2013:0269881113482530.

11. Briesacher BA, Limcangco MR, Simoni-Wastila L, et al. The quality of antipsychotic drug prescribing in nursing homes. Arch Intern Med. 2005;165(11):1280-5.

12. Van Dijk K, de Vries CS, Van den Berg P, Brouwers JJ, De Jong-van den Berg L. Drug utilisation in Dutch nursing homes. Eur J Clin Pharmacol. 2000;55(10):765-71.

13. Lindesay J, Matthews R, Jagger C. Factors associated with antipsychotic drug use in residential care: changes between 1990 and 1997. Int J Geriatr Psychiatry. 2003;18(6):511-9.

14. Azermai M, Vander Stichele RR, Van Bortel LM, Elseviers MM. Barriers to antipsychotic discontinuation in nursing homes: an exploratory study. Aging Ment Health. 2014;18(3):346-53.

15. Kleijer B, Van Marum R, Egberts A, et al. The course of behavioral problems in elderly nursing home patients with dementia when treated with antipsychotics. Int Psychogeriatr. 2009;21(05):931-40.

16. Nijk RM, Zuidema SU, Koopmans RT. Prevalence and correlates of psychotropic drug use in Dutch nursing-home patients with dementia. Int Psychogeriatr. 2009;21(3):48593.

17. Ballard C, Hanney ML, Theodoulou M, et al. The dementia antipsychotic withdrawal trial (DART-AD): long-term follow-up of a randomised placebo-controlled trial. Lancet Neurol. 2009;8(2):151-7.

18. van Reekum R, Clarke D, Conn D, et al. A randomized, placebo-controlled trial of the discontinuation of long-term antipsychotics in dementia. Int Psychogeriatr. 2002;14(02):197-210.

19. Ajzen I. The theory of planned behavior. Organ Behav Hum Decis Process. 1991;50(2):179-211.

This article is protected by copyright. All rights reserved. 
20. Walker A, Grimshaw J, Armstrong E. Salient beliefs and intentions to prescribe antibiotics for patients with a sore throat. Br J Health Psychol. 2001;6(4):347-60.

21. Ajzen I. Constructing a TpB questionnaire: Conceptual and methodological considerations. Working Paper, University of Massachusetts, Amherst, 2002

22. Scott IA, Anderson K, Freeman CR, Stowasser DA. First do no harm: a real need to deprescribe in older patients. Med J Aust. 2014;201(7):390-2.

23. Fishbein M, Ajzen I. Predicting and changing behavior: The reasoned action approach. New York:Psychology Press, Taylor \& Francis Group; 2010.

24. Cohen-Mansfield J, Jensen B. Physicians' perceptions of their role in treating dementiarelated behavior problems in the nursing home: Actual practice and the ideal. JAMDA. 2008;9(8):552-7.

25. Colenda CC, Leist JC, Rapp SR. Survey of physician practices for community-dwelling agitated dementia patients. Int J Geriatr Psychiatry. 1996;11(7):635-44.

26. Vereniging specialisten ouderengeneeskunde [Internet]. Utrecht: Verenso; 2016 [cited 2016 09-02]. Available from: http://www.verenso.nl/

27. Fishbein M, Ajzen, I. Belief, Attitude, Intention, and Behavior: An Introduction to Theory and Research. Reading: Addison-Wesley; 1975.

28. Bloch F, Thibaud M, Dugué B, Brèque C, Rigaud A-S, Kemoun G. Psychotropic drugs and falls in the elderly people: updated literature review and meta-analysis. J Ageing Health. 2010:0898264310381277.

29. Harding R, Peel E. 'He was like a zombie': off-label prescription of antipsychotic drugs in dementia. Med Law Rev. 2013;21(2):243-77.

30. Cornegé-Blokland E, Kleijer BC, Hertogh CM, van Marum RJ. Reasons to prescribe antipsychotics for the behavioral symptoms of dementia: a survey in Dutch nursing homes among physicians, nurses, and family caregivers. JAMDA. 2012;13(1):80. e1-. e6.

31. Cohen-Mansfield J, Jensen B. Nursing home physicians' knowledge of and attitudes toward nonpharmacological interventions for treatment of behavioral disturbances associated with dementia. JAMDA. 2008;9(7):491-8.

32. Wood-Mitchell A, James IA, Waterworth A, Swann A, Ballard C. Factors influencing the prescribing of medications by old age psychiatrists for behavioural and psychological symptoms of dementia: a qualitative study. Age Ageing. 2008;37(5):547-52.

33. Backhouse T, Killett A, Penhale B, Burns D, Gray R. Behavioural and psychological symptoms of dementia and their management in care homes within the East of England: a postal survey. Aging Ment Health. 2014;18(2):187-93.

34. Hardeman $W$, Johnston $M$, Johnston D, Bonetti D, Wareham N, Kinmonth AL. Application of the Theory of Planned Behaviour in behaviour change interventions: A systematic review. Psychol Health. 2002;17(2):123-58.

This article is protected by copyright. All rights reserved. 
35. Brazil, K, Galway, K, Carter, G, van der Steen, JT. Providing Optimal Palliative Care for Persons Living with Dementia: A Comparison of Physician Perceptions in the Netherlands and the United Kingdom. J Palliat Med, 2016; [ahead of print].

36. Chróinín, DN, Chróinín, CN, Beveridge, A. Factors influencing deprescribing habits among geriatricians. Age Ageing, 2015; 44(4):704-708.

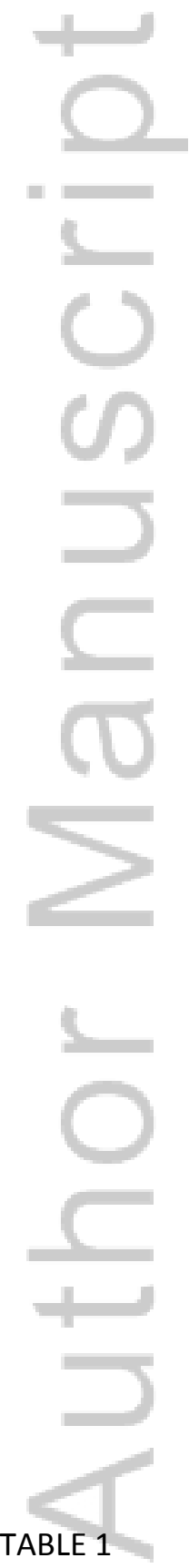

This article is protected by copyright. All rights reserved. 
Table 1. Demographics of the elderly care physicians and their prescriptions $(N=41)$

\begin{tabular}{|c|c|c|}
\hline Characteristics & $\mathbf{N}(\%)$ & Mean (SD) \\
\hline Age & & $47(10)$ \\
\hline Experience in elderly care & & $16(9)$ \\
\hline \multicolumn{3}{|l|}{ Gender } \\
\hline$=$ Male & $11(27)$ & \\
\hline Female & $30(73)$ & \\
\hline Small-scale & $16(39)$ & \\
\hline Traditional & $6(15)$ & \\
\hline Combination of both & $19(46)$ & \\
\hline Average number of weeks until discontinuation & & $14(16)$ \\
\hline Residents currently using antipsychotic & & $22(15)$ \\
\hline $0-10 \%$ & $10(24)$ & \\
\hline $11-20 \%$ & $17(42)$ & \\
\hline $21-30 \%$ & $8(20)$ & \\
\hline $31-40 \%$ & $2(5)$ & \\
\hline $41-50 \%$ & $1(2)$ & \\
\hline $51-60 \%$ & $3(7)$ & \\
\hline More than $60 \%$ & - & \\
\hline Availability and use of the alternatives to antipsychotics & Availability & Use \\
\hline Tools (blanket, table/chair) & $32(80)$ & $26(65)$ \\
\hline
\end{tabular}

This article is protected by copyright. All rights reserved. 


\begin{tabular}{lcc}
\hline Occupational therapy & $37(92)$ & $37(93)$ \\
Going along with patient & $35(87)$ & $34(85)$ \\
Sensory stimulation & $34(85)$ & $33(83)$ \\
Cognitive therapies & $30(75)$ & $23(74)$ \\
Medication & $38(95)$ & $37(93)$ \\
\hline Other therapies (acupuncture, music etc.) & $19(48)$ & $17(43)$ \\
\hline Non available & - & - \\
\hline
\end{tabular}

This article is protected by copyright. All rights reserved. 
TABLE 2

Table 2. Frequencies of the single items of the TPB $(N=41)$

Statements

Disagree (1-2) (N Neutral (3) (N

Agree (4-5) (N (\%))

(\%))

(\%))

\section{Direct Attitude}

Prescribing antipsychotics is not desirable...

...for dementia

$4(10)$

$10(24)$

$27(66)$

...for behavioural problems

$4(10)$

$18(44)$

$19(46)$

Beliefs about treatment effects

Prescribing antipsychotics results in...

...physiological calmness of the

$13(32)$

$20(49)$

patient

...smaller risk of harm to other

$17(42)$

$19(46)$

patients

...suppressed behavioural

$8(20)$

$14(34)$

$19(46)$

problems

...smaller risk of harm to staff

$18(44)$

$18(44)$

....psychological rest for patient

$16(39)$

8 (19)

$17(42)$

This article is protected by copyright. All rights reserved. 


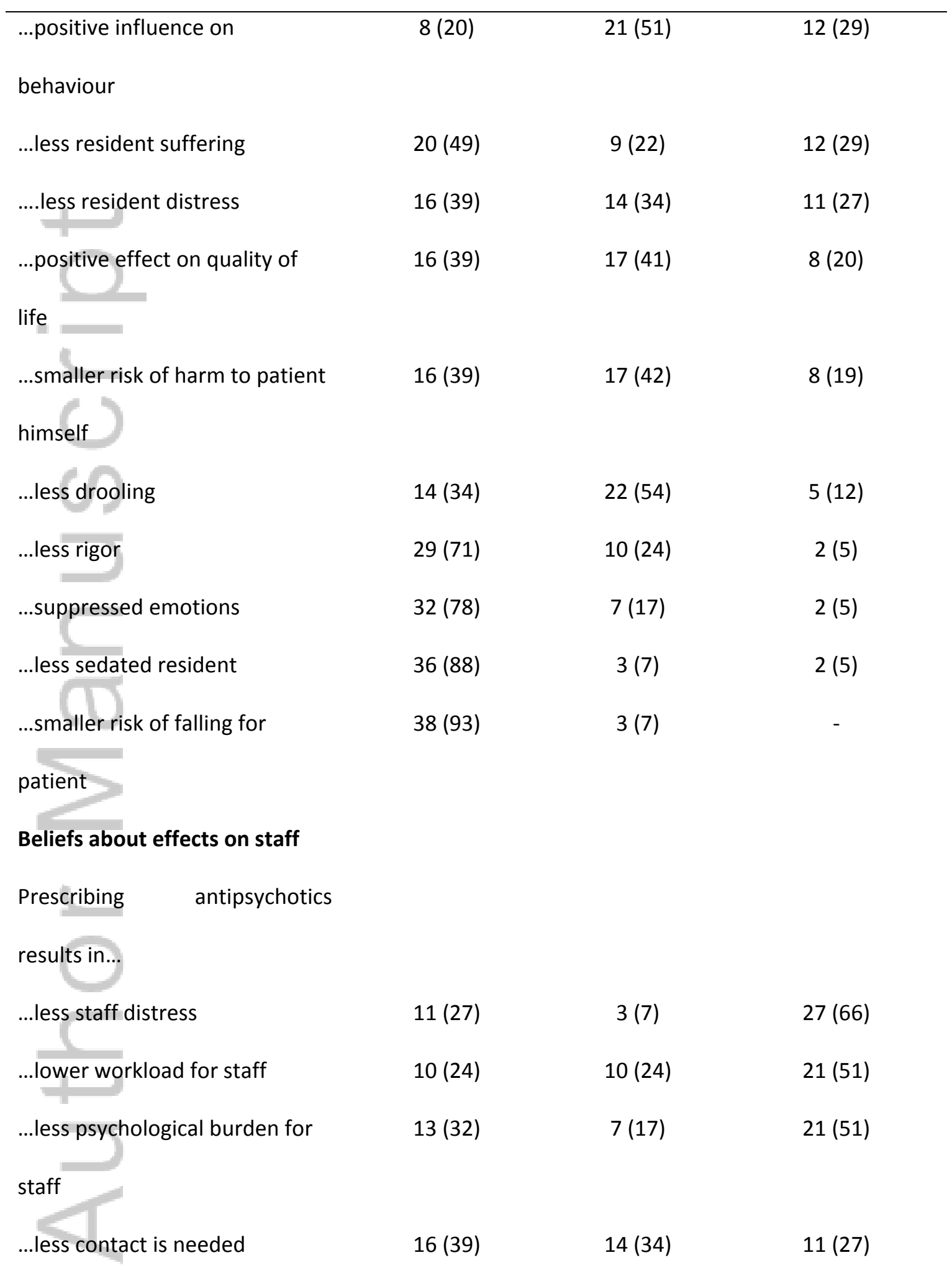

This article is protected by copyright. All rights reserved. 


\begin{tabular}{|c|c|c|c|}
\hline ...easier contact with patient & $25(61)$ & $7(17)$ & $9(22)$ \\
\hline ...higher ease of care & $18(44)$ & $16(39$ & $7(17)$ \\
\hline ...more supervision of patient & $30(73)$ & $6(15)$ & $5(12)$ \\
\hline \multicolumn{4}{|l|}{ Social pressures } \\
\hline \multicolumn{4}{|c|}{ According to physician ... believes antipsychotics should be discontinued } \\
\hline$=$ Family & $32(78)$ & $8(20)$ & $1(2)$ \\
\hline Physician & $36(88)$ & $4(10)$ & $1(2)$ \\
\hline Psychologist & $37(90)$ & $4(10)$ & - \\
\hline Nursing assistant & $40(98)$ & $1(2)$ & - \\
\hline Nurse & $39(95)$ & $2(5)$ & - \\
\hline Resident & $39(95)$ & $2(5)$ & - \\
\hline
\end{tabular}

According to physician ... demands antipsychotics

should be discontinued

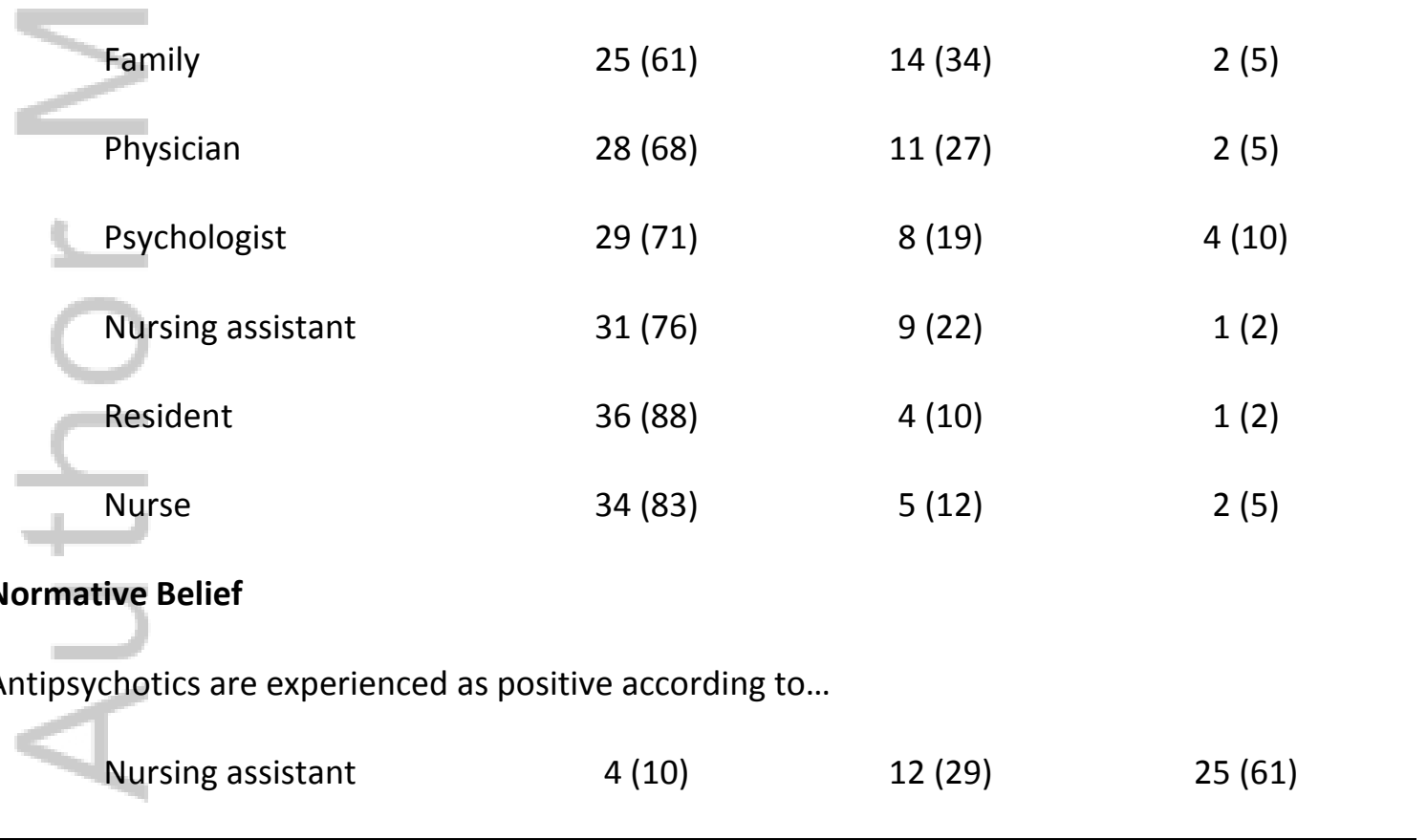

This article is protected by copyright. All rights reserved. 


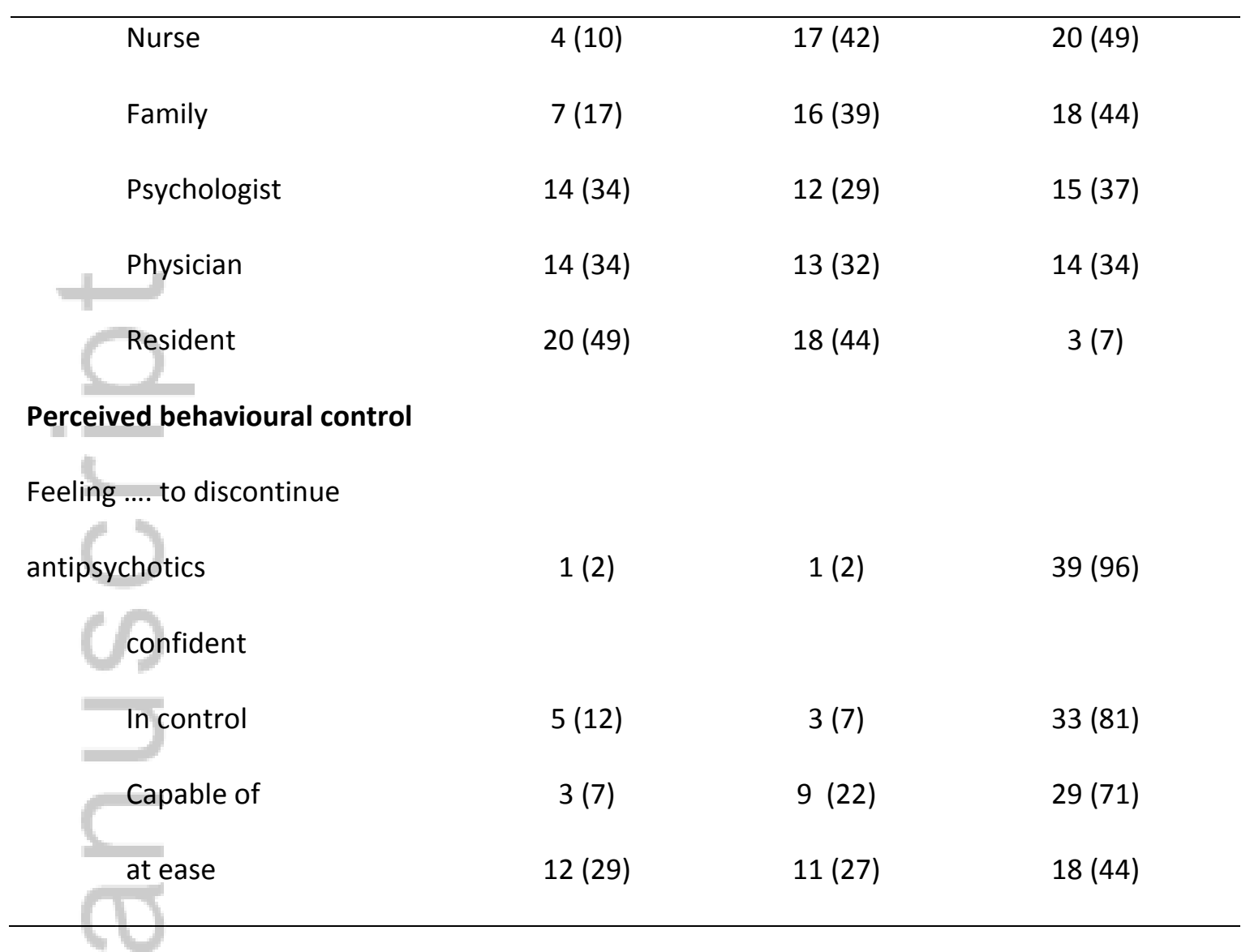

This article is protected by copyright. All rights reserved. 
TABLE 3

Table 3: Intention to call for antipsychotics of nurses $(\mathrm{N}=41)$

N (\%) Mean

(SD)

\section{Intention}

In the cases where I consider it desirable...

...I want to/ am inclined to critically reconsider the prescribed antipsychotics

and stop if possible (mean (SD))

Indicated intention low $(<5)^{\dagger}$

$14(34)$

Indicated intention high (5) $†$

$27(65)$

This article is protected by copyright. All rights reserved. 
† mean score of the two questions, each ranging from 1-5

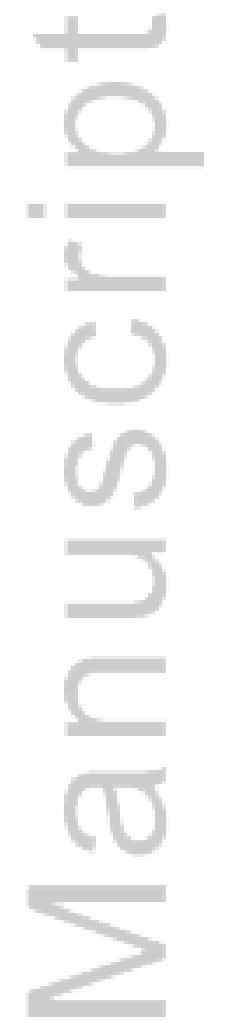

TABLE 4

Table 4. Scale means and means per group $(\mathrm{N}=41)$

\begin{tabular}{llll}
\hline Statements & Scale & Indicated & Indicated \\
& Mean & intention low & intention \\
& (SD) & $(0-4.5)($ Mean & high \\
& (SD)) & (5) (Mean \\
\hline
\end{tabular}

This article is protected by copyright. All rights reserved. 


\begin{tabular}{llll}
\hline & & & $(\mathrm{SD}))$ \\
\hline Direct Attitude & $3.5(.71)$ & $3.5(.57)$ & $3.6(.78)$ \\
Beliefs about treatment & $2.8(.46)$ & $2.8(.45)$ & $2.8(.48)$ \\
effects & & & \\
Beliefs about effects on & $2.8(.58)$ & $2.7(.57)$ & $2.9(.59)$ \\
staff & & & \\
Social pressures & $1.8(.41)$ & $1.8(.25)$ & $1.7(.47)$ \\
Normative Belief & $3.1(.56)$ & $3.2(.46)$ & $3.2(.61)$ \\
Perceived behavioural & $3.9(.75)$ & $3.4(.67)$ & $4.1(.69) *$ \\
control & & & \\
\hline
\end{tabular}

${ }^{*} p$-value $<0.05$ for comparison between experimental conditions (intention high vs. low) using an independent t-test

This article is protected by copyright. All rights reserved. 


\section{University Library}

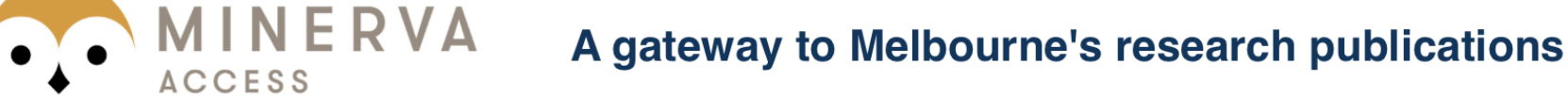

Minerva Access is the Institutional Repository of The University of Melbourne

Author/s:

Janus, SIM;van Manen, JG;Zuidema, SU;Snijder, C;Drossaert, CHC;lizerman, MJ

Title:

Reasons for (not) discontinuing antipsychotics in dementia

Date:

2018-01-01

Citation:

Janus, S. I. M., van Manen, J. G., Zuidema, S. U., Snijder, C., Drossaert, C. H. C. \& Ijzerman, M. J. (2018). Reasons for (not) discontinuing antipsychotics in dementia. PSYCHOGERIATRICS, 18 (1), pp.13-20. https://doi.org/10.1111/psyg.12280.

Persistent Link:

http://hdl.handle.net/11343/293219 